Review Article

\title{
The physiological and pathophysiological aspects of the sphenoid sinus: a review
}

\author{
Manish Munjal ${ }^{1 *}$, Suneet Sethi ${ }^{1}$, Shubham Munjal'2, Vidushi Gupta², Hem lata Badyal'2, \\ Joginder K Sidhu², Garima Sharma ${ }^{2}$
}

${ }^{1}$ Department of ENT and HNS, ${ }^{2}$ Department of Physiology, Dayanand Medical College Ludhiana, Punjab, India

Received: 29 October 2020

Accepted: 09 December 2020

\section{*Correspondence:}

Dr. Manish Munjal,

E-mail: manishmunjaldr@yahoo.com

Copyright: (C) the author(s), publisher and licensee Medip Academy. This is an open-access article distributed under the terms of the Creative Commons Attribution Non-Commercial License, which permits unrestricted non-commercial use, distribution, and reproduction in any medium, provided the original work is properly cited.

\begin{abstract}
The sphenoid sinus among the paranasal sinuses, with its deep location and obstruction at the level of its ostium, is the commonest cause of occipital or vertex headache. Limited intervention reverts the intricate mucociliary physiology of the sinus. The surgery, a sphenoidotomy, is aptly captioned, the "functional endoscopic sinus surgery", for the Sphenoid. The unique physio-pathology of the Sphenoid sinus shall be elaborated.
\end{abstract}

Keywords: Sphenoid sinus, Physiology, Pathology

\section{INTRODUCTION}

The significance of these air spaces is one of the most difficult problems in human evolution. Similar to the other paranasal sinuses the function of the sphenoid sinus is not quite clear. Blaney 1990 broadly categorized the significance of existence of paranasal sinuses in humans as structural and functional. ${ }^{1}$ Structural includes reduction in the cranial weight, shock absorption, accommodation of an increased size of the head, include interspaces between the architecture, remove functionless bone, secondary to cranial modification and be a vestigial olfactory organ.

The sinuses function as air reservoirs, secrete mucus and humidify and warm up the inspired air. Moreover, they insulate the vital structures and provide resonance to one's voice.

The Sphenoid sinus with its ostium located in its anterior wall and deeply seated in the narrow spheno-ethmoidal recess is likely to retain the secretions so produced by its lining. This is consequent to, alteration of the sinus ventilation as well as its drainage at the level of the ostium. The physiology and pathophysiology of the Sphenoid sinus needs introspection.

\section{REVIEW OF LITERATURE}

\section{Physiological aspects}

The sphenoid sinuses are lined by ciliated pseudo stratified columnar epithelium. It is thin and pink in colour. Underneath lies the tunica propria which contains different types of cells and glands that secrete mucus.

The entire mucous membrane is covered with a mucous blanket, which is responsible for trapping bacteria and for warming and humidifying the inspired air currents, a function performed in conjunction with other paranasal sinuses. This blanket keeps moving towards the natural ostium of the sphenoid sinus in a spiral manner and is renewed every 10-15 minutes by Hilding. ${ }^{2}$

Messerklinger 1966 on analysis of the mucociliary clearance of the sphenoids concluded that the mucus produced in the sinuses does not travel in a random fashion to their ostia, but follows a definite pathway that 
is determined genetically. Although these pathways maybe impeded or even blocked by various pathologic conditions, their direction is not significantly altered. ${ }^{3}$

Ciliary beat is the most important mechanism responsible for mucociliary clearance, i.e. the constant motion of the mucous blanket as a result of which mucus is propelled into the nasopharynx. The ciliary beat is best in fluid medium and in humid environment. From the sphenoid sinus the mucus flows to the natural ostium to the spheno-ethmoidal recess and ultimately drains into the posterior choanae of the nose just above the tubal orifice to reach the nasopharynx and pharynx to be finally swallowed and destroyed in the stomach (Figure 1,2).

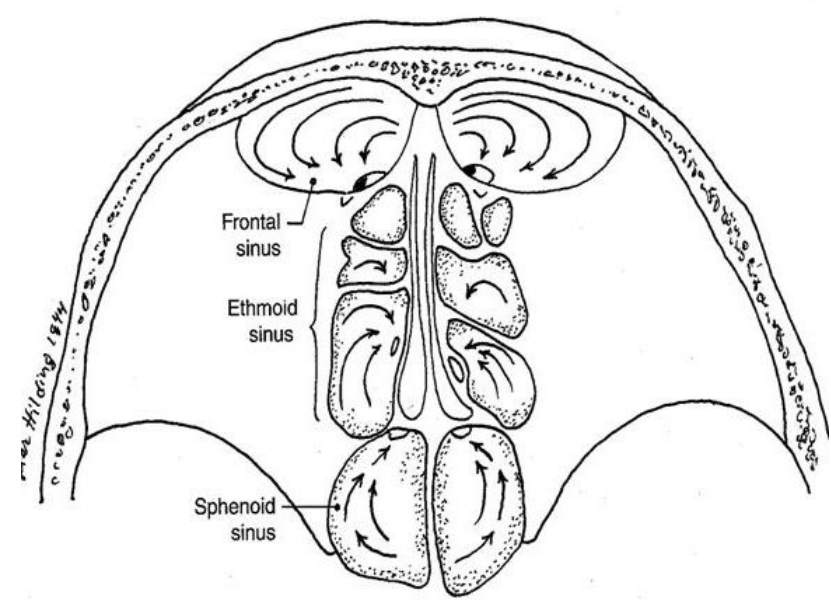

Figure 1: Schematic mucociliary drainage of the Sphenoid, ethmoid and frontal sinuses on axial view.

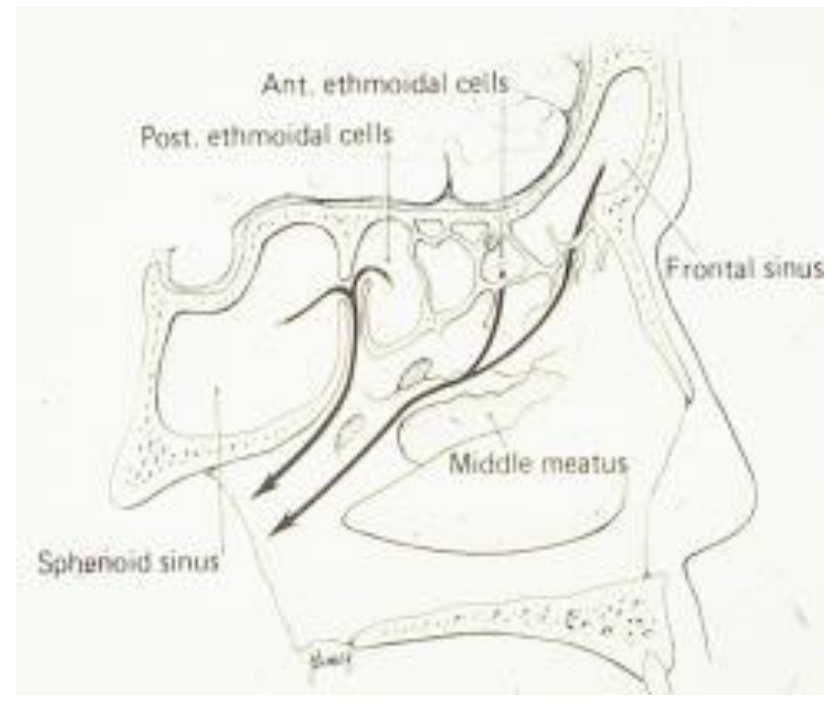

Figure 2: Schematic mucociliary drainage of the sphenoid, ethmoid and frontal sinuses on saggittal view.

Stammberger et al, Weir et al attributed two main factors for the normal functioning of the sinuses 1) ventilation that depends on patency of the ostium and prechamber i.e. the sphenoethmoidal recess 2) drainage that depends on the mucus, it's amount, composition and ciliary beat. $^{4,5}$

\section{Pathophysiology}

Any alteration in the normal ventilation or drainage of the sinus leads to a disturbance of the normal mucociliary flow and thereby a diseased sinus.

The presence of "mucosal contact" areas have been identified as the single most important factor in the pathogenesis of sinus pathology. Messerklinger 1978. This can happen as a result of varied etiologies. ${ }^{6}$ These lead on to obstruction of the mucociliary drainage pathway. This happens first at the narrow anatomical communicating channel- the sphenoethmoidal recess. Phelps. The persistence of "mucosal contact" at this site causes cessation of ciliary beat. ${ }^{7}$

\section{Etiological / predisposing factors}

1) anatomical variants 2) mucociliary abnormalities i) primary a. primary ciliary dyskinesia b. cystic fibrosis c. Young's syndrome ii) Secondary a. allergy b. bacterial infection mucociliary clearance can be impaired by hypoxia temperature variations, dehydration medications (antihistamines, anticholinergics), and cigarette smoke, foreign bodies, infections, environmental irritants, trauma and tumours. ${ }^{8}$ 3) immune deficiency, which maybe primary or idiopathic type and the secondary type due to HIV infection or being on immunosuppressant drugs 4) allergy. More than $90 \%$ of sinusitis is due to pathology in the anterior ethmoid region and limited surgery to treat these distal sites can re-establish ventilation and drainage.

As can be seen from the list of etiological factors the sphenoid sinus is not affected in isolation. In fact, it is the least to be affected in an isolated pathology and its involvement is usually secondary to the involvement of the anterior group of sinuses. Weir et al. ${ }^{5}$

Less than $3 \%$ of the inflammatory lesions of the sinuses involve the sphenoid sinus primarily, Lew et al $1983 .{ }^{9}$ while primary carcinoma of the sphenoid sinus occurs in less than $0.05 \%$ of sinus malignancies. Harbison et al $1984 .^{10}$

Isolated sphenoid sinus disease is an uncommon disease that affects $1-2.7 \%$ of patients with diagnosis of paranasal sinus disease. Wyllie, Pearlman, Hnatuk, Lawson, Sethi. ${ }^{1-}$ 14 Metson et al found the incidence isolated sphenoid sinus disease to be about $2 \% .^{15}$

\section{The sphenoid sinus pathology}

The anatomic relationships of the sphenoid sinus direct the nasal airflow below the sphenoid ostia; thereby few bacteria or inhaled irritants are carried to this deep-seated sinus. Moreover, the lining mucosa has fewer glands and 
hence produces less amount of mucus. Therefore, pathologic involvement of the sphenoid sinus is not that common. Van Alyea, Lawson. ${ }^{16,17}$

Pathologic conditions arising in and about the sphenoid sinus can be varied and include inflammatory processes, primary benign and malignant tumours invading from adjacent structures and distant metastatic disease. Levine. ${ }^{18}$

Anatomical variation such as sphenoid septation, malposition of the ostium, a deviated nasal septum, and an enlarged middle turbinate make one more susceptible to infection. Lawson et al. ${ }^{17}$

\section{Sphenoid sinusitis}

Less than $3 \%$ of inflammatory lesions involve the sphenoid sinus primarily. The sinus, in these cases is found full of purulent material with underlying inflammatory granulation tissue. Lew. ${ }^{9}$

Lawson et al found that $80 \%$ of lesions in isolated sphenoid sinus involvement were inflammatory disease. ${ }^{17}$

\section{Fungal sinusitis of the sphenoid}

Isolated fungal infection of the sphenoid sinus is a rare entity by Klossek et al. ${ }^{19}$

Allergic fungal rhinosinusitis is a non-invasive infection characterized by the presence of allergic mucin which is comprised of eosinophils and Charcot- Leyden crystals alternating with layers of mucus, creating a lamellar, inspissated pattern. Fungal hyphae are scattered throughout the allergic mucin but there is no evidence of invasion into the host tissue by Schell. ${ }^{20}$

A fungal ball is also a non-invasive form of disease in which the fungus forms a mass of intertwined hyphae without host invasion by Schell. ${ }^{20}$

Chronic invasive and acute invasive/fulminant forms reveal hyphal invasion of host tissue with a slower granulomatous progressive angioinvasive and neuroinvasive pattern in the latter by Schell. ${ }^{20}$

Aspergillus is the most common organism involved in fungal sphenoid sinusitis, with the formation of fungal balls as the predominant pathology. Johrsdoerfer, Schell. ${ }^{20,21}$

Management of allergic fungal sinusitis requires endoscopic removal of the inspissated debris and mucus and primary drainage of the affected sinus followed by postoperative topical steroids. Systemic steroids have also been recommended. Henick, Kennedy. ${ }^{22}$

Management of non-invasive fungal rhinosinusitis involves surgical extirpation of all allergic mucinous and fungal debris with restoration of drainage and aeration to the affected sinuses. Henick, Kennedy, Lee et al. ${ }^{22,23}$

Invasive fungal sinusitis requires bimodal treatment, surgical debridement and antifungal agents. Henick and Kennedy. ${ }^{22}$

\section{Sphenoid polyposis}

Polyps can occur as isolated sphenoid sinuses lesions but more commonly they occur in association with polyps of posterior ethmoid cells. The patient usually has a history of rhinosinusitis, postnasal discharge and headache. Polyps in paranasal sinuses result from local upheaval of the sinus mucosa with mucous membrane hyperplasia secondary to chronic inflammation by Issacs. ${ }^{24}$

\section{Mucoceles and pyoceles of the sphenoid}

They are the most frequently reported sphenoid, 'space occupying lesions. The pathogenesis is related to obstruction of the sphenoid ostium (secondary mucocele) or mucous, retention cyst expansion (primary mucocele). Fungal infection of the sphenoid sinuses may lead to obstruction of the sinus ostium and subsequent retention of secretions. Marple. ${ }^{25}$ consequently there is formation of an expansile cystic lesion in the sphenoid sinuses i.e. a mucocele. Muneer et al. ${ }^{26}$ As the mucocele enlarges, pressure causes resorption of the surrounding bone. Issacs. $^{24}$

Differentiation between sphenoid cysts, mucoceles, pyoceles and abscesses is often difficult because they all may contain clear but thickened creamy secretions which on culture and sensitivity examination may be reported negative/inconclusive, however, because of their similarity in development and natural history, they are considered as one group. Nurgent et al, Wyllie. ${ }^{11,27}$

Adult rhino sinusitis diagnostic criteria were defined in, by the American academy of Otolaryngology-Head and Neck Surgery during a meeting of the multidisciplinary Rhino sinusitis task force (RTF). In 2003, this definition was amended to require confirmatory radiographic or nasal endoscopic or physical examination findings in addition to suggestive history. ${ }^{28}$

\section{CONCLUSION}

On vis a vis the physiology and pathophysiology of the sphenoid sinus, surgical intervention is undertaken in sinusitis, at the ostium to facilitate drainage and ventilation of the sinus and thereby revert till now inactive mucociliary clearance.

\section{Funding: No funding sources \\ Conflict of interest: None declared \\ Ethical approval: Not required}




\section{REFERENCES}

1. Blaney SP. Why paranasal sinuses? J Laryngol Otol. 1990;104(9):690

2. Hilding 1957 Hilding AC. Ciliary streaming in the lower respiratory tract. Am J Physiol Lega Cont. 1957;191(2):404-10.

3. Messerklinger W. On the drainage of the human paranasal sinuses under normal and pathological conditions. 1. Monatsschrift fur Ohrenheilkunde und Laryngo-Rhinologie. 1966;100(1-2):56.

4. Stammberger H, Hawke M. Surgical operative technique. Essent Funct Endosc Sin Surg. 1993:172.

5. Weir N, Golding-wood DG. Scott-Brown's Text book of Rhinology.

6. Messerklinger W. Endoscopic operations. Endoscopy of the Nose. Munich: Urban and Schazenberg. 1978;4950.

7. Phelps PD. Radiology of the Nose and Paranasal Sinuses. In: Mackay and Bull, editors. Scott Brown's Otorhinolaryngology, Head and Neck Surgery. 6th ed. London: Elsevier. 1997;4/3/2.

8. Mackay IS and Lund VJ. Surgical management of sinusitis. Scott Brown's Otolaryngology, 6th ed., Butterworth Hienemann, Oxford. 1997.

9. Lew D, Southwick FS, Montgomery WW, Weber AL, Baker AS. Sphenoid sinusitis: a review of 30 cases. New Eng J Medic. 1983;309(19):1149-54.

10. Harbison JW, Lessell S, Selhorst Jb. Neuroophthalmology of sphenoid sinus carcinoma. Brain. 1984;107(3):855-70.

11. Wyllie III JW, Kern EB, Djalilian M. Isolated sphenoid sinus lesions. Laryngoscope. 1973;83(8):1252-65.

12. Pearlman SJ, Friedman WH, Potter GD, Lawson $\mathrm{W}$, Biller HF. Isolated sphenoid sinus disease. Laryngoscope. 1989;99(7):716-20.

13. Hnatuk LA, Macdonald RE, Papsin BC. Isolated sphenoid sinusitis: the Toronto Hospital for Sick Children experience and review of the literature. J Otolaryngol. 1994;23(1):36.

14. Sethi DS. Isolated sphenoid lesions: diagnosis and management. Otolaryngol Head Neck Surg. 1999;120(5):730-6.

15. Metson R, Gliklich RE. Endoscopic treatment of sphenoid sinusitis. Otolaryngol Head Neck Surg. 1996;114(6):736-44.
16. Van Alyea OE. Sphenoid sinus: anatomic study, with consideration of the clinical significance of the structural characteristics of the sphenoid sinus. Arch Otolaryngol. 1941;34(2):225-53.

17. Lawson W, Reino AJ. Isolated sphenoid sinus disease: an analysis of 132 cases. Laryngoscope. 1997;107(12):1590-5.

18. Levine $\mathrm{H}$. The sphenoid sinus, the neglected nasal sinus. Arch Otolaryngol. 1978;104(10):585-7.

19. Klossek JM, Peloquin L, Fourcroy PJ, Ferrie JC, Fontanel JP. Aspergillomas of the sphenoid sinus: a series of 10 cases treated by endoscopic sinus surgery. Rhinology. 1996;34(3):179-83.

20. Schell WA. Unusual fungal pathogens in fungal rhinosinusitis. Otolaryngol Clinics North Am. 2000;33(2):367-73.

21. Jahrsdoerfer RA, Ejercito VS, Johns MM, Cantrell RW, Sydnor JB. Aspergillosis of the nose and paranasal sinuses. Am J Ootolaryngol. 1979;1(1):614.

22. Henick DH, Kennedy DW. Fungal sinusitis. Advanced endoscopic sinus surgery. St Louis: Mosby. 1995:69-80.

23. Lee LA, Lee TJ, Huang CC. Endoscopic sinus surgery for solitary abducens palsy in patients with isolated sphenoid sinus disease: report of four cases. Chang Gung Medic J. 2002;25(10):689-94.

24. Isaacs RS, Donald PJ. Sphenoid and sellar tumors. Otolaryngol Clinics North Am. 1995;28(6):1191229.

25. Marple BF. Allergic fungal rhinosinusitis: surgical management. Otolaryngol Clinics North Am. 2000;33(2):409-18.

26. Muneer A, Jones NS. Unilateral abducens nerve palsy: a presenting sign of sphenoid sinus mucoceles. J Laryngol Otol. 1997;111(7):644-6.

27. Nugent GR, Sprinkle P, Bloor BM. Sphenoid sinus mucoceles. J Neurosurg. 1970;32(4):443-51.

28. Patel A, American Academy of Otolaryngology, Bulletin. 1999;18(2).

Cite this article as: Munjal M, Sethi S, Munjal S, Gupta V, Badyal HL, Sidhu JK et al. The physiological and pathophysiological aspects of the sphenoid sinus: a review. Int J Otorhinolaryngol Head Neck Surg 2021;7:192-5. 